\title{
Digital Non-Linear Equalization for Flexible Capacity Ultradense WDM Channels for Metro Core Networking
}

\author{
Arlunno, Valeria; Zhang, Xu; Larsen, Knud J.; Zibar, Darko; Tafur Monroy, Idelfonso
}

Published in:

Proceedings of the European Conference on Optical Communication (ECOC) 2011

Publication date:

2011

Document Version

Publisher's PDF, also known as Version of record

Link back to DTU Orbit

Citation (APA):

Arlunno, V., Zhang, X., Larsen, K. J., Zibar, D., \& Tafur Monroy, I. (2011). Digital Non-Linear Equalization for Flexible Capacity Ultradense WDM Channels for Metro Core Networking. In Proceedings of the European Conference on Optical Communication (ECOC) 2011 (pp. Tu.3.K.6). Optical Society of America.

http://www.ecoc2011.org/

\section{General rights}

Copyright and moral rights for the publications made accessible in the public portal are retained by the authors and/or other copyright owners and it is a condition of accessing publications that users recognise and abide by the legal requirements associated with these rights.

- Users may download and print one copy of any publication from the public portal for the purpose of private study or research.

- You may not further distribute the material or use it for any profit-making activity or commercial gain

- You may freely distribute the URL identifying the publication in the public portal 


\title{
Digital Non-Linear Equalization for Flexible Capacity Ultradense WDM Channels for Metro Core Networking
}

\author{
Valeria Arlunno, Xu Zhang, Knud J. Larsen, Darko Zibar and Idelfonso Tafur Monroy \\ DTU Fotonik, Department of Photonics Engineering, Technical University of Denmark, DK-2800 Kgs. Lygnby, Denmark. \\ vaar@fotonik.dtu.dk
}

\begin{abstract}
We experimentally demonstrate that digital non-linear equalization allows for using independent tunable DFB lasers spaced at $12.5 \mathrm{GHz}$ for ultradense WDM PM-QPSK flexible capacity channels for metro core networking.

OCIS codes: (060.1660) Coherent communications; (060.4510) Optical communications
\end{abstract}

\section{Introduction}

Rigid and coarse granularity of wavelength-division-multiplexing (WDM) systems leads to inefficient capacity utilization. In flexible optical WDM (FWDM), spectral resources are allocated in a flexible and dynamic way; channel spacing and center wavelength are not fixed on the ITU-T grid, resulting in higher spectral efficiency [1-2]. Even in this higher-efficient bandwidth allocation scenario, the bandwidth is non optimally utilized as large guard bands are still employed. Ultra-dense (UD) WDM with a channel spacing of less than $25 \mathrm{GHz}$, may provide an evolutionary path from conventional infrastructures towards more scalable and spectrally efficient networks. This trend is supported by the increased demand for more capacity, flexibility and upgradeability of transmission technique while keeping some legacy ones, in particular in the metro segments of the optical network. Increasing the number of wavelengths within a fixed optical bandwidth (e.g., $\mathrm{C}$ band), by decreasing the spacing between neighboring channels, allows an increase in the system capacity without requiring of high-speed electronics (e.g., $>40 \mathrm{~Gb} / \mathrm{s}$ ), while keeping compatibility with the $10 \mathrm{~Gb} / \mathrm{s}$ SONET/SDH equipment. UDWDM systems with no aliasing condition (i.e. with channel spacing higher than the double the baud rate) have been studied, with particular attention to limitations introduced by fiber nonlinearity effects such as Four-Wave Mixing (FWM), Cross-Phase Modulation (XPM), fiber chromatic dispersion-induced symbol intersymbol interference (ISI) [3]. However, to cope with the required bandwidth efficiency, future UDWDM schemes will need to use extremely close channel spacing; this implies taking measures to mitigate the resultant detrimental effects from crosstalk and neighboring channels interferences.

In this paper we experimentally demonstrate that by employing a digital nonlinear equalizer, such as a Decision Feedback Equalizer (DFE), we can mitigate inter-channel interference, improve overall system performance in terms of OSNR and allow for a channel spacing of $12.5 \mathrm{GHz}$ using conventional independent DFB light sources for a $40 \mathrm{~Gb} / \mathrm{s}$ ultradense 3 channel WDM PM-QPSK system with coherent detection. Our proof of principle experiment demonstrates that in a $50 \mathrm{GHz}$ bandwidth (in accordance to the ITU-T grid) up to 4 channels can be transmitted, improving the total bit rate from $40 \mathrm{~Gb} / \mathrm{s}$ to $160 \mathrm{~Gb} / \mathrm{s}$ per slot, with small changes in the electronic equipment.

\section{System setup}

The general outline of the experimental setup for the UDWDM polarization multiplexing (PM) QPSK coherent optical (CO) system is shown in Fig. 1. At the transmitter side three carriers are generated employing three independent tunable distributed feedback lasers (DFB) with $10 \mathrm{MHz}$ linewidth; one of them is fixed at a central wavelength $\left(\lambda_{c}\right)$ of $1550.511 \mathrm{~nm}$. Different channel spacing values $\Delta \lambda(20,18,16,14,13,12,11 \mathrm{and} 10 \mathrm{GHz})$ between the 3 carriers have been realized by changing the wavelength of the right $\left(\lambda_{\mathrm{r}}\right)$ and left $\left(\lambda_{1}\right)$ DFB lasers as to have the desired spectral separation. A $40 \mathrm{GHz}$ bandwidth photodiode and an Electrical Spectrum Analyzer are used to verify correct spacing between the three channels. A polarization beam splitter divides the signal into two orthogonal polarization which are then fed into two optical I/Q modulator (nested Mach-Zender modulator). A $10 \mathrm{~Gb} / \mathrm{s}$ pattern generator (PPG) generates the pseudo random binary sequence (PRBS), with $2^{15}-1$ bit length, that drives the two QPSK modulators. Two uncorrelated branches of polarization orthogonal QPSK signals are then combined with a polarization beam combiner (PBC) to generate the PM QPSK signals, at $10 \mathrm{Gbaud} / \mathrm{s}$. An $80 \mathrm{~km}$ span of standard single mode fiber (SMF) is used as optical transmission link. At the receiver side an optical tunable band-pass filter $(0.33 \mathrm{~nm}$ or $37.5 \mathrm{GHz}$ full width at half maximum, FWHM, at $1550 \mathrm{~nm})$ is employed before the optical pre-amplifier; a second band-pass filter $(0.5 \mathrm{~nm}$ or $62.5 \mathrm{GHz}$ FWHM at $1550 \mathrm{~nm})$ rejects the out of band ASE noise. An external cavity laser (ECL) with $100 \mathrm{kHz}$ linewidth is used as local oscillator (LO). The PM 


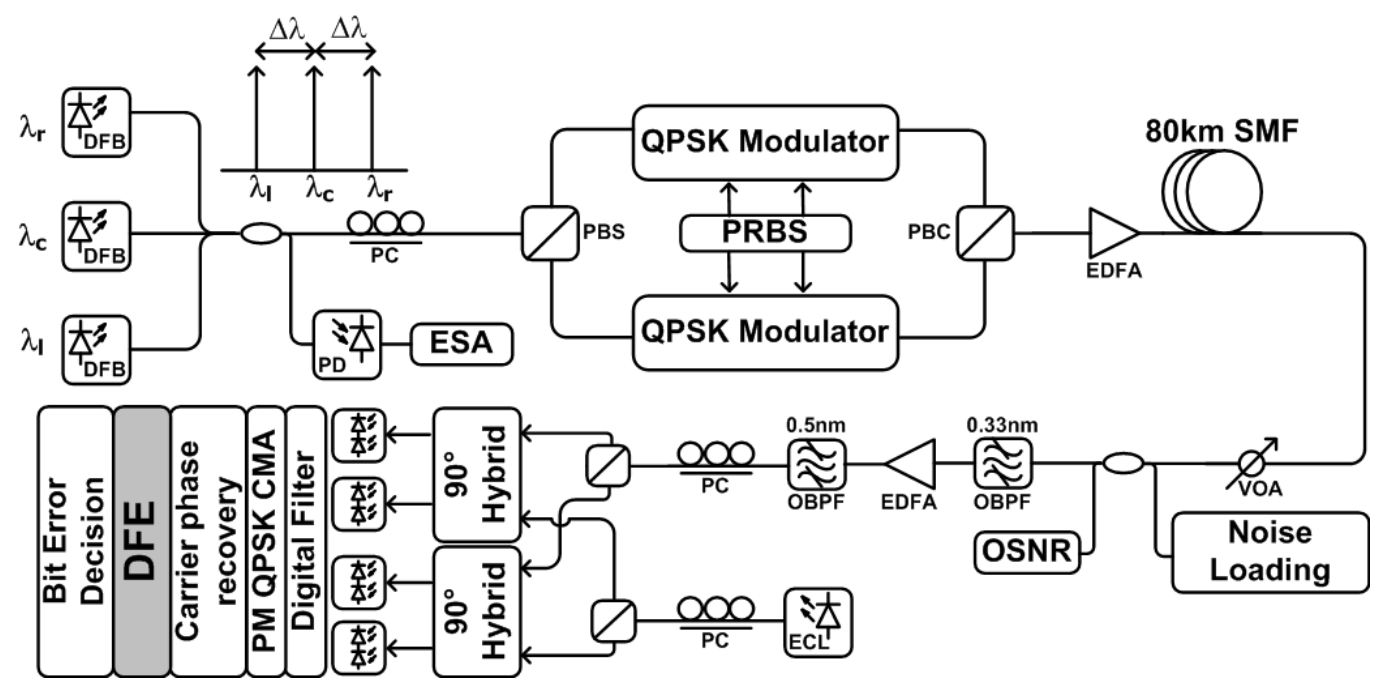

Fig.1. Experiment setup of UDWDM PM QPSK system; DFB: Distributed feedback laser; PD: 40G photodiode; ESA: Electrical Spectrum Analyzer; PC: polarization controller; PBS: polarization beam splitter; PBC: polarization beam combiner; EDFA: erbium-doped fiber amplifier; VOA: variable optical attenuator; OBPF: optical band-pass filter; ECL: external cavity laser.

coherent receiver consists of two $90^{\circ}$ hybrids and balanced photodetectors. The photodetected inphase and quadrature outputs are sampled at $40 \mathrm{GS} / \mathrm{s}$ for offline demodulation. Digital signal processing (DSP) algorithms implement digital filtering, PM QPSK constant modulus algorithm (CMA) equalization, QPSK carrier phase recovery and bit error decision.

As the channel distortion or the ISI of a transmission system is too severe for a linear equalizer to mitigate the channel impairments, non-linear equalizer has been used. A DFE is a non-linear structure that uses previous detector decision to eliminate the ISI on pulses currently demodulated. The DFE equalizer will not amplify the noise, cause according to its structure, the equalization process is done through the feedback, noiseless, data. A nonlinear DFE consisting of a feedforward filter (FFE) and a feedback filter (FBE) is used in our DSP receiver, after the carrier phase recovery block, to improve the system performances [4]. The taps of the two equalizers are adjusted using a least mean square (LMS) stochastic algorithm.

\section{Results}

After optimize the PM CMA algorithm structure, we've investigated the impact of a nonlinear decision feedback equalizer consisting of a 1 tap feedforward filter (FFE) and a 7 or 9 taps feedback filter (FBE) on the system performances (this structure is indicated as DFE in the graphs); the digital filter is then re-optimized to improve further the BER curves. The measured BER performances of the UDWDM PM QPSK for back-to-back (B2B) system are shown in Fig. 2. Fig. 2(a) shows the BER experimental performances as a function of the measured OSNR for a spacing of $14 \mathrm{GHz}$ without nonlinear equalization, with the nonlinear equalization structure DFE and with further optimization of the digital filter. It can be observed that the non-linear equalization and the optimization
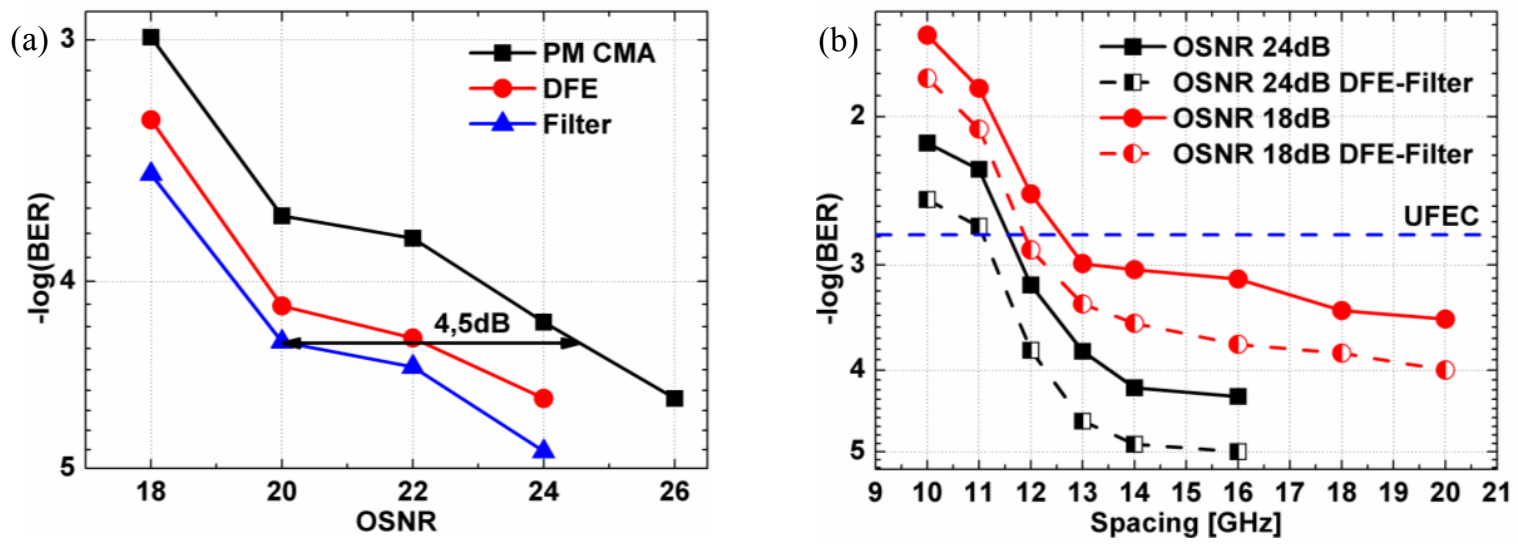

Fig.2.(a) BER as a function of OSNR for a spacing of $14 \mathrm{GHz}$ without nonlinear equalization, with DFE and with optimization of the digital filter. (b) BER as a function of the spacing for two fixed values of OSNR with and without nonlinear equalization. 
of the digital filter afterward, can improve the system performances up to $4.5 \mathrm{~dB}$ in terms of OSNR and $0.6 \mathrm{~dB}$ in terms of BER. The BER versus carrier spacing for two fixed value of OSNR is shown if Fig. 2(b); the results show that the DSP implementation can improve the experimental BER results for all the different spacing. For a fix spacing the algorithm can improve the BER result, while for a fix BER value the use of DSP, it allows closer channel. Of particular importance is $12.5 \mathrm{GHz}$ of spacing which, thanks to the nonlinear equalization, shows performances better then the UFEC limit for both the chosen OSNR.

(a)

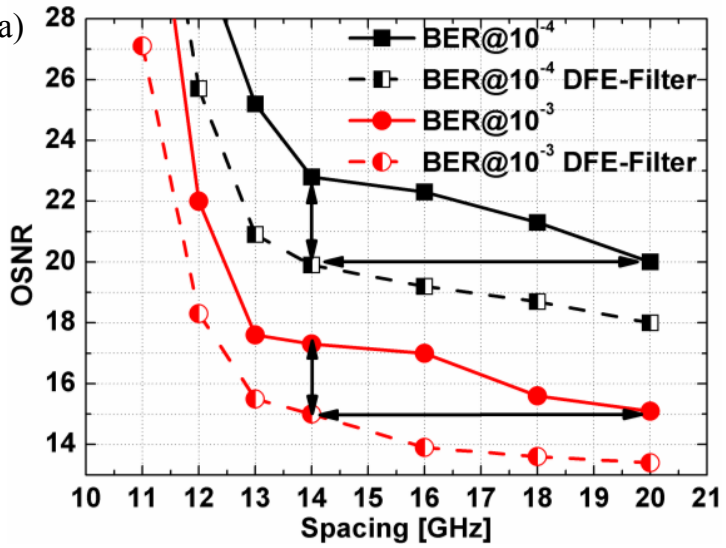

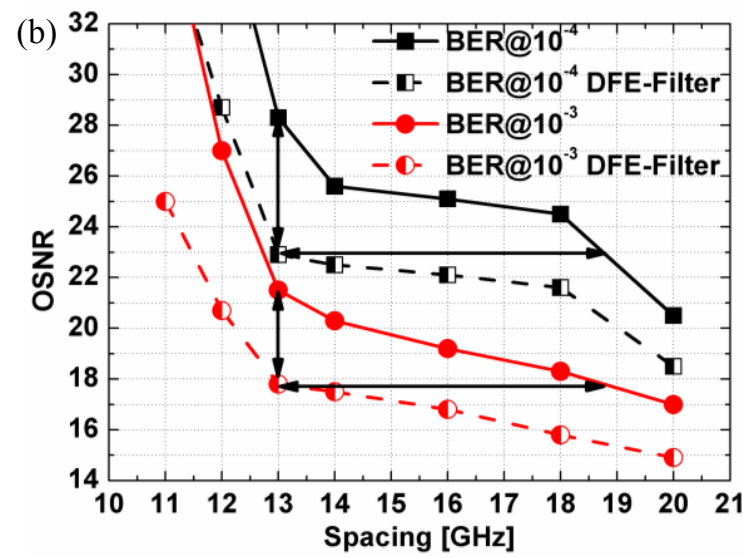

Fig.3.(a) OSNR as a function of the spacing for two fixed values of BER with and without nonlinear equalization for Back-to-Back. (b) OSNR as a function of the spacing for two fixed values of BER with and without nonlinear equalization for $80 \mathrm{Km}$ of SMF.

Fig. 3 shows OSNR performance as a function of the spacing with and without nonlinear equalization for Backto-Back and $80 \mathrm{~km}$ of SMF optical transmission are presented. The BER is fixed $@ 10^{-4}$ and @1 $10^{-3}$, both below the UFEC level. The improvement enabled by the DSP implementation on both BER and spacing values is remarkable. As shown in Fig. 3(a) we can improve $\sim 2-3 \mathrm{~dB}$ for OSNR with the same spacing value between the carriers; on the other hand for a fix OSNR the carriers can be generated $6 \mathrm{GHz}$ closer, moving from $20 \mathrm{GHz}$ of spacing, case where we have no aliasing, to $14 \mathrm{GHz}$ of spacing. The same behavior is obtained for $80 \mathrm{~km}$ of optical transmission. It can be observed in Fig. 3(b) that with the same spacing value between the carriers, the improvement in terms of OSNR is $\sim 3 \mathrm{~dB}$ for BER@10 $10^{-3}$ and $\sim 5 \mathrm{~dB}$ for BER@10 $10^{-4}$; for the same OSNR then the carriers can be $\sim 6 \mathrm{GHz}$ closer, moving to $\sim 19 \mathrm{GHz}$ to $13 \mathrm{GHz}$. It should be noticed that the length of the FBE is 7 or 9 taps compared to 1 tap for the FFE, indicating that the signal is affected by non-linearities.

The results obtained suggest more efficient and flexible utilization of the available bandwidth. In case of ITU-T grid with $50 \mathrm{GHz}$ spacing, one single $40 \mathrm{~Gb} / \mathrm{s}$ signal can be transmitted per slot. Using the proposed UDWDM with DSP non linear equalization, up to 4 channels $(12.5 \mathrm{GHz}$ of spacing) per slot can be transmitted with a total bit-rate of $160 \mathrm{~Gb} / \mathrm{s}$, with small changes in the electronic equipment. Better results per slot could also be obtained with a single carrier higher data rate signal $(100 \mathrm{~Gb} / \mathrm{s})$, but this would imply higher speed electronics and no more compatibility with the existing $10 \mathrm{~Gb} / \mathrm{s}$ SONET/SDH equipment.

\section{Conclusion}

We have experimentally demonstrated that by employing a DFE nonlinear equalizer in the DSP domain, an ultradense WDM PM QPSK can be realized. Performances below the UFEC limit are obtained for very closed channel spacing (down to $12.5 \mathrm{GHz}$ ). In a $50 \mathrm{GHz}$ ITU-T grid, the structure proposed allows to quadruple the number of user in a flexible way, moving from a total bit rate of $40 \mathrm{~Gb} / \mathrm{s}$ per slot to $160 \mathrm{~Gb} / \mathrm{s}$.

\section{Acknowledgement}

The research leading to these results has received funding from the European Community's Seventh Framework Programme [FP7/2007-2013] under grant agreement $\mathrm{n}^{\circ} 258644$, CHRON project.

\section{References}

[1] A. Patel, P. Ji, J. Jue and T. Wang, "Survivable Transparent Flexible Optical WDM (FWDM) Networks," in Proc. Optical Fibre Communication Conf., ( Los Angeles, CA, 2011), paper OTul2

[2] A. Patel, P. Ji, J. Jue and T. Wang, "Defragmentation of Transparent Flexible Optical WDM (FWDM) Networks," in Proc. Optical Fibre Communication Conf., ( Los Angeles, CA, 2011), paper OTuI8

[3] M. Wu and W. Way, "Fiber Nonlinearity Limitations in Ultra-Dense WDM systems," JLT 22, 6 (2004)

[4] D. Zibar, R. Sambaraju, A. Caballero, J. Herrera and I. Tafur Monroy, "Carrier Recovery and Equalization for Photonic-Wireless Links with Capacities up to $40 \mathrm{~Gb} / \mathrm{s}$ in 75-110 GHz Band," in Proc. Optical Fibre Communication Conf., ( Los Angeles, CA, 2011), paper OThJ4 